\title{
Corneal pharmacokinetics of voriconazole and posaconazole following intrastromal injection and posaconazole eye drops instillation in rats
}

Julie Gueudry, Laetitia Le Goff, Fabien Lamoureux, Tony Pereira, Sabine Levefre, Romy Razakandrainibe, Damien Costa, Jean Jacques Ballet, Marc Muraine \& Loïc Favennec 
DOI: $10.1080 / 02713683.2020 .1749669$

Corneal pharmacokinetics of voriconazole and posaconazole following intrastromal injection and posaconazole eye drop instillation in rats

Julie GUEUDRY, MD, PhD ${ }^{1,2}$; Laetitia LE GOFF, PharmD, $\mathrm{PhD}^{1}$; Fabien LAMOUREUX, PharmD, PhD ${ }^{3}$; Tony PEREIRA ${ }^{3}$; Sabine LEFEVRE ${ }^{2}$; Romy RAZAKANDRAINIBE, PhD

1. Damien COSTA; PharmD, PhD ${ }^{1}$; Jean Jacques BALLET, MD, PhD ${ }^{1}$; Marc MURAINE, $\mathrm{MD}, \mathrm{PhD}^{2}$ and Loïc FAVENNEC MD, $\mathrm{PhD}^{1}$

${ }^{1}$ EA7510 "Epidémio-surveillance et circulation des parasites dans l'environnement" University of Rouen Normandie, Rouen, France

${ }^{2}$ Department of Ophthalmology - Charles Nicolle University Hospital, Rouen, France

${ }^{3}$ Department of Clinical Pharmacology - Charles Nicolle University Hospital, Rouen, France

Running title: Intrastromal and eye drop triazoles in rat cornea

Correspondence and reprint requests to:

Dr Julie Gueudry

Department of Ophthalmology

Charles Nicolle Hospital

22 Boulevard Gambetta

76031 ROUEN - FRANCE 
Tel: (33) $232888057 \quad$ Fax: (33) 232888046

E-mail: julie.gueudry@chu-rouen.fr

Keywords: cornea; fungal keratitis; voriconazole; posaconazole; antifungal drugs; triazoles

\section{ABSTRACT}

Purpose/Aims: Infectious keratitis is a major cause of visual impairment and blindness

worldwide. Common difficulties in treating fungal keratitis prompt new therapeutic

possibilities. In this study, intrastromal voriconazole and posaconazole, and topical

posaconazole, were tested for their potential to obtain therapeutic cornea concentrations.

Materials and Methods: Pharmacokinetics of triazole intracorneal/eye drop administration was studied in rats. Sixty-two rats were treated either by voriconazole or posaconazole. Twenty-nine and 33 rats received intrastromal injection of voriconazole solution $(1 \mu \mathrm{l}, 10$ $\mathrm{mg} / \mathrm{ml})$ and posaconazole solution $(1 \mu \mathrm{l}, 18 \mathrm{mg} / \mathrm{ml})$, respectively, administered under microscopic examination with a 32 gauge needle in the left cornea. Posaconazole $(1.8 \%$ solution) eye drops were used. Cornea and plasma concentrations were determined using 2D HPLC separation and tandem MS, at $30 \mathrm{~min}, 3 \mathrm{~h}, 6 \mathrm{~h}, 24$ h, 48 h, 72 h, and 144 h (6 days) post-intrastromal injection. The entire rat cornea was used for chromatography analyses.

Results: In anesthetized rats, single intracorneal injection resulted, after $30 \mathrm{~min}$, in respectively $>300 \mathrm{ng} / \mathrm{mg}$ and $>260 \mathrm{ng} / \mathrm{mg}$ cornea concentrations, dropping to low levels within hours, while staying low in plasma. The effect of hourly posaconazole eye drops resulted in $>10 \mathrm{ng} / \mathrm{mg}$ cornea concentration, which was maintained with instillations every 2 
and then every 4 hours.

Conclusion: Our results show that there is little interest of intrastromal triazole administration due to the short duration of high cornea concentrations obtained after intracorneal injection. Posaconazole eye drops maintain therapeutic cornea concentrations in rats and could be used to treat severe infectious keratitis.

ARTICLE

\section{Introduction}

Infectious keratitis is a major cause of visual impairment and blindness worldwide, prompting new therapeutic possibilities. Appropriate data on ocular concentrations of antiinfectious agents, which may be extrapolated from in vitro studies of microorganism sensitivities, may be indicative of clinical efficacy. While eye drops are generally used as first line therapy, some agents are administered intrastromally, i.e. intracorneally, in order to obtain elevated cornea concentrations, without having to use toxic systemic doses. ${ }^{1}$ Intrastromal injections may be used to treat severe infectious keratitis especially fungal keratitis and less frequently Acanthamoeba keratitis. ${ }^{2,3}$ Combined intrastromal and topical or systemic anti-fungal treatments have been used in fungal keratitis, nevertheless limited information is available on resulting cornea concentrations obtained with topical and intrastromal agents. ${ }^{4-7}$ Except for amphotericin B, resulting cornea concentrations after intrastromal administration of antifungal agents, including voriconazole, are not presently documented. ${ }^{5}$ However, the most effective molecule used for intrastromal injections in severe fungal keratitis is not yet known. The pharmacokinetics of voriconazole is known in the cornea, in the aqueous humor and in the vitreous after eye drop instillation but not after intrastromal injection. ${ }^{4,6,8,9}$ For posaconazole, an alternative broad-spectrum triazole agent, 
which shows promise in treating refractory fungal keratitis, ocular pharmacokinetics was studied in one clinical case report but in absence of cornea concentration measurement. ${ }^{10}$ Our team has previously studied the corneal pharmacokinetics of voriconazole eye drops and has shown the importance of a high frequency of instillation to obtain therapeutic concentrations. ${ }^{6}$ Thus, the aim of this study was to document for the first time in rats the effectiveness of a one-shot intrastromal voriconazole and posaconazole administration, and repeated posaconazole eye drop instillations, to maintain therapeutic cornea concentrations.

\section{Materials and methods}

Voriconazole and posaconazole solutions $(10 \mathrm{mg} / \mathrm{ml}$ and $18 \mathrm{mg} / \mathrm{ml}$, respectively) were prepared by diluting lyophilisates (Vfend, Pfizer, Paris, France, and Noxafil, MSD, Courbevoie, France) in sterile injection water.

Five-week-old male SPF Sprague-Dawley, 150 g rats (Janvier, Le Genest Saint Isle, France) were housed 3 per cage. This study was approved by the ad hoc local ethical committee (No. 00755.02) and all experiments were performed in compliance with European Community regulations for laboratory animal care and use (Directive 2010/63/UE). Rats were anesthetized intraperitoneally by mixed $2 / 3$ ketamine and $1 / 3$ xylazine hydrochlorides. Sixtytwo rats were treated either by voriconazole or posaconazole. Twenty-nine and 33 rats received intrastromal voriconazole and posaconazole injections consisting of $1 \mu 1$ of above solutions, respectively, administered under microscopic examination in the left eye $(10 \mu \mathrm{l}$ Hamilton syringes, 32 gauge needles). At sequential times post-injection (Table 1), 5 or 4 animals were sacrificed, and cornea and blood samples were collected and frozen. Posaconazole ( $1.8 \%$ solution) eye drops were administered for 6 days in the right eye of 28 animals (see regimens and sampling times in Table 2).

Cornea samples were thawed and weighed in microtubes, and $100 \mu \mathrm{l}$ of an extraction solution containing the internal standards (deuterated VCZ-d5 or PSZ-D5, $0.1 \mu \mathrm{g} / \mathrm{ml}$ in 
acetonitrile) was added to each cornea sample (or to $50 \mu$ of plasma). The mixtures were vortexed for $10 \mathrm{sec}$, sonicated for $15 \mathrm{~min}$ (cornea samples), centrifuged, and $1 \mathrm{ml}$ of supernatant was injected into the chromatographic system. The liquid chromatographytandem mass spectrometry procedure was performed as previously described. ${ }^{6,11}$ For voriconazole and posaconazole, lower limits of detection and quantification were $0.005 \mu \mathrm{g} / \mathrm{ml}$ and $0.1 \mu \mathrm{g} / \mathrm{ml}$, respectively (i.e. rounded $0.005 \mathrm{ng} / \mathrm{mg}$ and $0.1 \mathrm{ng} / \mathrm{mg}$ of cornea, assuming that $>90 \%$ of cornea weight was due to its water content). ${ }^{12}$ The assay was validated according to the FDA and EMA guidelines for bioanalytical methods validation. Within-run and between runs accuracy and precision were $<15 \%$ of nominal concentrations and $<15 \% \mathrm{CV}$ for the LCMS/MS assay.

Concentrations were expressed in means +/- 1 SD. Differences between groups were investigated using Student's $t$ test, thus assuming normal like distributions of values (Komolgorov-Smirnov $\mathrm{p}>0.01$ in most groups of 5 rats). $\mathrm{p}$ values lower than 0.05 were considered significant.

\section{Results}

As shown in table 1 , mean cornea voriconazole concentration exceeded $300 \mathrm{ng} / \mathrm{mg}$ at 30 min post-intrastromal injection and decreased sharply from 30 min to 3 hours $(p<0.005)$. Concentrations were very low from $6 \mathrm{~h}$ to day 6 . Plasma levels remained very low from 30 min until day 6. Mean posaconazole cornea concentration reached $264.3 \mathrm{ng} / \mathrm{mg}$ at $30 \mathrm{~min}$, decreased sharply from 30 min to 3 hours $(\mathrm{p}<0.005)$, and then decreased further from $3 \mathrm{~h}$ to $48 \mathrm{~h}(\mathrm{p}<0.005)$ and remained very low until $144 \mathrm{~h}$. In contrast, corresponding posaconazole plasma concentrations increased until $72 \mathrm{~h}(\mathrm{p}=0.02)$ and plateaued on day $6(0.4 \mu \mathrm{g} / \mathrm{ml})$.

Mean cornea concentration following hourly posaconazole eye drop instillations peaked at more than $70 \mathrm{ng} / \mathrm{mg}$ at $3 \mathrm{~h}$ post-first instillation, and then dropped until $24 \mathrm{~h}$ post- 
first instillation ( $\mathrm{p}=0.02$, Table 2). Mean cornea concentration following 2-hourly instillations (i.e. 7 times a day) decreased to $14.96 \mathrm{ng} / \mathrm{mg}(\mathrm{p}=0.01)$, and to $11.21 \mathrm{ng} / \mathrm{mg}(\mathrm{p}<0.05$, MannWhitney test) after 4-hourly instillations (i.e. 4 times a day).

\section{Discussion}

Cornea concentrations of more than $250 \mathrm{ng} / \mathrm{mg}$ obtained $30 \mathrm{~min}$ post-intrastromal injections of both voriconazole or posaconazole were much higher than previously reported fungicidal concentrations. ${ }^{13-16}$ Such levels, however, were short-lived since at $3 \mathrm{~h}$, they were reduced by factors of 280 and 7.5 , respectively, and low concentrations were further observed. For voriconazole, data are consistent with the reported lack of benefit using intrastromal instead of topical therapy as an adjunct to natamycin in human fungal keratitis. ${ }^{17}$, ${ }^{18}$ For posaconazole, data reveal a similar sharp drop in cornea concentrations within a few hours. Plasma concentrations were constantly very low for voriconazole while interestingly increasing until more than $0.40 \mathrm{ng} / \mathrm{ml}$ at $72 \mathrm{~h}$ for posaconazole, consistent with slow posaconazole absorption and elimination observed in several species including rats. ${ }^{19}$ Moreover, repeated eye drop installation resulted in some systemic absorption and progressive diffusion and accumulation of posaconazole in rat plasma.

Cornea posaconazole concentrations assessed for the first time after eye drop instillation were found dependent on instillation frequency. A previously published case report about Fusarium solani keratitis and endophthalmitis showed lower concentrations of $0.25 \mu \mathrm{g} / \mathrm{ml}$ (vitreous) and $0.9 \mu \mathrm{g} / \mathrm{ml}$ (aqueous humor) obtained using concomitant oral and eye drop posaconazole administrations, however corneal posaconazole concentration was not analyzed. ${ }^{10}$ Data suggest that posaconazole eye drops may offer an alternative with fewer side effects to the systemic route successfully used in the management of refractory fungal keratitis; ${ }^{20}$ although posaconazole was previously shown not to be effective on Fusarium 
solani species complex..$^{21}$

Rapid triazole diffusion might be facilitated by low molecular weight for the partially hydrophilic voriconazole, and a solubilizer for the lipophilic posaconazole. ${ }^{22}$ The absence of cornea reservoir effect previously reported for topical voriconazole in rats was confirmed after intrastromal voriconazole and posaconazole injection, and for topical posaconazole by the dependence of cornea concentrations on instillation frequency. ${ }^{6}$ Triazole diffusion contrasts with high molecular amphotericin B which topically does not enter stroma when corneal epithelium is left in place, and for which intrastromal injections resulted in persisting corneal levels well above MICs of most fungi for 7 days. ${ }^{5}$ Moreover, intrastromal injection of amphotericin B at a concentration of less than $10 \mu \mathrm{g}$ per $0.1 \mathrm{ml}$ has been previously reported to be safe in rabbit corneas, ${ }^{23}$ and is used to treat refractory fungal keratitis in clinical practice. $^{24}$

Present data show that there is little interest of intrastromal triazole administration due to the short duration of high cornea concentrations obtained after intracorneal injection. Posaconazole eye drops maintain therapeutic cornea concentrations in rats and could be used to treat severe infectious keratitis.

\section{Acknowledgments}

We are grateful to Charles Hervouet for technical assistance and to Nikki Sabourin-Gibbs for editing assistance.

\section{Declaration of interest statement}

None

Funding: Financial support was obtained from the University of Rouen Normandie, Rouen, 
France. R.R is a postdoc fellow supported by the university of Rouen Normandie, Rouen,

France and the Normandie region, France.

1. Girmenia C, Iori AP. An update on the safety and interactions of antifungal drugs in stem cell transplant recipients. Expert Opin Drug Saf 2017:16(3): 329-339.

2. Bang S, Edell E, Eghrari AO, Gottsch JD. Treatment with voriconazole in 3 eyes with resistant acanthamoeba keratitis. Am J Ophthalmol 2010:149(1): 66-69.

3. Austin A, Lietman T, Rose-Nussbaumer J. Update on the management of infectious keratitis. Ophthalmology 2017:124(11): 1678-1689.

4. Sponsel W, Chen N, Dang D, Paris G, Graybill J, Najvar LK, Zhou L, Lam KW, Glickman R, Scribbick F. Topical voriconazole as a novel treatment for fungal keratitis. Antimicrob Agents Chemother 2006:50(1): 262-268.

5. Qu L, Li L, Xie H. Corneal and aqueous humor concentrations of amphotericin b using three different routes of administration in a rabbit model. Ophthalmic Res 2010:43(3): 153-158.

6. Gueudry J, Le Goff L, Compagnon P, Lefevre S, Colasse E, Aknine C, Duval F, Francois A, Razakandrainibe R, Ballet JJ et al. Evaluation of voriconazole anti-acanthamoeba polyphaga in vitro activity, rat cornea penetration and efficacy against experimental rat acanthamoeba keratitis. J Antimicrob Chemother 2018.

7. Sharma N, Sahay P, Maharana PK, Singhal D, Saluja G, Bandivadekar P, Chako J, Agarwal T, Sinha R, Titiyal JS et al. Management algorithm for fungal keratitis: The tst (topical, systemic, and targeted therapy) protocol. Cornea 2019:38(2): 141-145.

8. Vemulakonda GA, Hariprasad SM, Mieler WF, Prince RA, Shah GK, Van Gelder RN. Aqueous and vitreous concentrations following topical administration of $1 \%$ voriconazole in humans. Arch Ophthalmol 2008:126(1): 18-22.

9. Clode AB, Davis JL, Salmon J, Michau TM, Gilger BC. Evaluation of concentration of voriconazole in aqueous humor after topical and oral administration in horses. Am J Vet Res 2006:67(2): 296-301.

10. Sponsel WE, Graybill JR, Nevarez HL, Dang D. Ocular and systemic posaconazole(sch56592) treatment of invasive fusarium solani keratitis and endophthalmitis. Br J Ophthalmol 2002:86(7): 829-830.

11. Lamoureux F, Duflot T, Woillard JB, Metsu D, Pereira T, Compagnon P, MorissePradier H, El Kholy M, Thiberville L, Stojanova J et al. Impact of cyp2c19 genetic polymorphisms on voriconazole dosing and exposure in adult patients with invasive fungal infections. Int J Antimicrob Agents 2016:47(2): 124-131.

12. Cahane M, Ben Simon GJ, Barequet IS, Grinbaum A, Diamanstein-Weiss L, Goller O, Rubinstein E, Avni I. Human corneal stromal tissue concentration after consecutive doses of topically applied $3.3 \%$ vancomycin. Br J Ophthalmol 2004:88(1): 22-24.

13. Halliday CL, Chen SC, Kidd SE, van Hal S, Chapman B, Heath CH, Lee A, Kennedy KJ, Daveson K, Sorrell TC et al. Antifungal susceptibilities of non-aspergillus filamentous fungi causing invasive infection in australia: Support for current antifungal guideline recommendations. Int J Antimicrob Agents 2016:48(4): 453458.

14. Uchida $\mathrm{K}$, Yokota $\mathrm{N}$, Yamaguchi $\mathrm{H}$. In vitro antifungal activity of posaconazole against various pathogenic fungi. Int J Antimicrob Agents 2001:18(2): 167-172. 
15. Morace G, Polonelli L, Group G. Voriconazole activity against clinical yeast isolates: A multicentre italian study. Int J Antimicrob Agents 2005:26(3): 247-253.

16. Pfaller MA, Messer SA, Hollis RJ, Jones RN, Group SP. Antifungal activities of posaconazole, ravuconazole, and voriconazole compared to those of itraconazole and amphotericin b against 239 clinical isolates of aspergillus spp. And other filamentous fungi: Report from sentry antimicrobial surveillance program, 2000. Antimicrob Agents Chemother 2002:46(4): 1032-1037.

17. Sharma N, Chacko J, Velpandian T, Titiyal JS, Sinha R, Satpathy G, Tandon R, Vajpayee RB. Comparative evaluation of topical versus intrastromal voriconazole as an adjunct to natamycin in recalcitrant fungal keratitis. Ophthalmology 2013:120(4): 677-681.

18. Narayana S, Krishnan T, Ramakrishnan S, Samantaray PP, Austin A, Pickel J, Porco T, Lietman T, Rose-Nussbaumer J. Mycotic antimicrobial localized injection (malin): A randomized clinical trial evaluating intrastromal injection of voriconazole. Ophthalmology 2019.

19. Agency EM. Posaconazole, scientific discussion. 2005.

20. Al-Hatmi AMS, Bonifaz A, Ranque S, Sybren de Hoog G, Verweij PE, Meis JF. Current antifungal treatment of fusariosis. Int J Antimicrob Agents 2018:51(3): 326-332.

21. Todokoro D, Suzuki T, Tamura T, Makimura K, Yamaguchi H, Inagaki K, Akiyama H. Efficacy of luliconazole against broad-range filamentous fungi including fusarium solani species complex causing fungal keratitis. Cornea 2019:38(2): 238-242.

22. Maertens J, Cornely OA, Ullmann AJ, Heinz WJ, Krishna G, Patino H, Caceres M, Kartsonis N, Waskin H, Robertson MN. Phase $1 \mathrm{~b}$ study of the pharmacokinetics and safety of posaconazole intravenous solution in patients at risk for invasive fungal disease. Antimicrob Agents Chemother 2014:58(7): 3610-3617.

23. Qu L, Li L, Xie H. Toxicity and pharmacokinetics of intrastromal injection of amphotericin b in a rabbit model. Curr Eye Res 2014:39(4): 340-347.

24. Garcia-Valenzuela E, Song CD. Intracorneal injection of amphothericin b for recurrent fungal keratitis and endophthalmitis. Arch Ophthalmol 2005:123(12): 1721-1723. 
Table 1. Cornea and plasma concentrations after voriconazole or posaconazole intrastromal injection.

\begin{tabular}{|c|c|c|c|c|}
\hline & Voriconazol & ration & Posaconazol & ration \\
\hline $\begin{array}{l}\text { Time post- } \\
\text { intrastromal } \\
\text { injection (h) }\end{array}$ & $\begin{array}{l}\text { Left cornea } \\
(\mathrm{ng} / \mathrm{mg})\end{array}$ & $\begin{array}{l}\text { Plasma } \\
(\mu \mathrm{g} / \mathrm{ml})\end{array}$ & $\begin{array}{l}\text { Left cornea } \\
\text { (ng/mg) }\end{array}$ & $\begin{array}{r}\text { Plasma } \\
(\mu \mathrm{g} / \mathrm{ml})\end{array}$ \\
\hline 0.5 & $\begin{array}{l}303 \\
\pm 93.22\end{array}$ & $\begin{array}{l}0.026 \\
\pm 0.017\end{array}$ & $\begin{array}{l}264.3 \\
\pm 109.4\end{array}$ & \\
\hline 3 & $\begin{array}{l}1.07 \\
\pm 0.37\end{array}$ & $\begin{array}{l}0.008 \\
\pm 0.001\end{array}$ & $\begin{array}{l}35.3 \\
\pm 14.0\end{array}$ & $\begin{array}{l}0.1 \\
\pm 0.1\end{array}$ \\
\hline 6 & $\begin{array}{l}0.19 \\
\pm 0.15\end{array}$ & $\begin{array}{l}0.010 \\
\pm 0.005\end{array}$ & & $\begin{array}{l}0.2 \\
\pm 0.1\end{array}$ \\
\hline 24 & $\begin{array}{l}0.05 \\
\pm 0.06\end{array}$ & $\begin{array}{l}0.001 \\
\pm 0.002\end{array}$ & & $\begin{array}{l}0.3 \\
\pm 0.1\end{array}$ \\
\hline 48 & $\begin{array}{l}0.10 \\
\pm 0.09\end{array}$ & 0 & $\begin{array}{l}0.3 \\
\pm 0.2\end{array}$ & $\begin{array}{l}0.3 \\
\pm 0.2\end{array}$ \\
\hline 72 & N.A. & & $\begin{array}{l}0.2 \\
\pm 0.2\end{array}$ & $\begin{array}{l}0.4 \\
\pm 0.1\end{array}$ \\
\hline 144 (6 days) & $\begin{array}{l}0.46 \\
\pm 0.55\end{array}$ & & $\begin{array}{l}0.6 \\
\pm 0.2\end{array}$ & $\begin{array}{l}0.4 \\
\pm 0.2\end{array}$ \\
\hline
\end{tabular}

Results expressed in mean concentrations +/- 1 SD in 5 rats for each post-injection time (except for voriconazole at 6 days and for posaconazole at $3 \mathrm{~h}$ and $6 \mathrm{~h}$ with 4 rats each) N.A.: not available 
Table 2. Posaconazole cornea concentration in the course of instillation sequences

Time post-first instillation*

Posaconazole right cornea mean

concentration $\mathrm{ng} / \mathrm{mg} \pm 1 \mathrm{SD}$

(Number of rats)

$3 \mathbf{h}$

$6 \mathrm{~h}$

$24 \mathrm{~h}$

$48 \mathrm{~h}$

$72 \mathrm{~h}$

144 h (6 days)
$74.1 \pm 27.8(4)$

$28.8 \pm 17.7(4)$

$19.2 \pm 4.9(5)$

$23.6 \pm 8.3(5)$

$6.3 \pm 3.6(5)$

$11.2 \pm 2.8(5)$

* Complete instillation sequence was from 8 AM to 8 PM hourly (13 times a day) during 2 days, then every 2 hours ( 7 times a day), and then every 4 hours (4 times a day) and rats were sacrificed at $3 \mathrm{~h}, 6 \mathrm{~h}, 24 \mathrm{~h}, 48 \mathrm{~h}, 72 \mathrm{~h}$, and $144 \mathrm{~h}$ post-first instillation.

Results expressed in mean concentrations +/- 1 SD in 5 rats for each post-first instillation time (except at $3 \mathrm{~h}$ and $6 \mathrm{~h}$ with 4 rats each). 